\title{
Bayesian Updating of Solar Panel Fragility Curves and Implications of Higher Panel Strength for Solar Generation Resilience
}

\author{
Luis Ceferino ${ }^{1,2,3}$, Ning Lin $^{3,4}$, Dazhi $\mathrm{Xi}^{4}$ \\ ${ }^{1}$ Department of Civil and Urban Engineering, New York University \\ ${ }^{2}$ Center for Urban Science and Progress, New York University \\ ${ }^{3}$ The Andlinger Center for Energy and the Environment, Princeton University \\ ${ }^{4}$ Department of Civil and Environmental Engineering, Princeton University
}

This paper has been submitted to the journal of Reliability Engineering \& System Safety for publication. 


\title{
Bayesian Updating of Solar Panel Fragility Curves and Implications of Higher Panel Strength for
} Solar Generation Resilience

\author{
Luis Ceferino ${ }^{1,2,3}$, Ning $\operatorname{Lin}^{3,4}$, Dazhi $\mathrm{Xi}^{4}$ \\ ${ }^{1}$ Department of Civil and Urban Engineering, New York University \\ ${ }^{2}$ Center for Urban Science and Progress, New York University \\ ${ }^{3}$ The Andlinger Center for Energy and the Environment, Princeton University \\ ${ }^{4}$ Department of Civil and Environmental Engineering, Princeton University
}

\begin{abstract}
Solar generation can become a major and global source of clean energy by 2050. Nevertheless, few studies have assessed its resilience to extreme events, and none have used empirical data to characterize the fragility of solar panels. This paper develops fragility functions for rooftop and ground-mounted solar panels calibrated with solar panel structural performance data in the Caribbean for Hurricanes Irma and Maria in 2017 and Hurricane Dorian in 2019. After estimating hurricane wind fields, we follow a Bayesian approach to estimate fragility functions for rooftop and groundmounted panels based on observations supplemented with existing numerical studies on solar panel vulnerability. Next, we apply the developed fragility functions to assess failure rates due to hurricane hazards in Miami-Dade, Florida, highlighting that panels perform below the code requirements, especially rooftop panels. We also illustrate that strength increases can improve the panels' structural performance effectively. However, strength increases by a factor of two still cannot meet the reliability stated in the code. Our results advocate reducing existing panel vulnerabilities to enhance resilience but also acknowledge that other strategies, e.g., using storage or deploying other generation sources, will likely be needed for energy security during storms.
\end{abstract}

Keywords: solar panels, fragility functions, hurricane hazards, Bayesian update, structural reliability

\section{INTRODUCTION}

As the world transitions towards cleaner energy sources, the power system infrastructure is rapidly changing. In 2019, installations of solar generators accounted for $40 \%$ of the electric generating capacity installed in the United States (Perea et al., 2019). Market and government projections state that solar generation will be $20-30 \%$ of the global electricity by 2050 (Shah \& Booream-Phelps, 2015; Sivaram \& Kann, 2016; Solaun \& Cerdá, 2019; The International Renewable Energy Agency, 2018). As a result, the resilience of the power system infrastructure is also changing. First, the design standards or the level of exposure of solar energy generating infrastructure can differ from current generation infrastructure. For example, engineers design nuclear plants or dams with risk category IV for safety in nuclear and hydroelectric generation, source of $20 \%$ and $7 \%$ electricity generation in the United States (U.S. Energy Information Administration, 2021). This category provides the highest structural reliability levels in the ASCE7-16 design code since failure "could pose a substantial hazard to the community" (American Society of Civil Engineers, 2017). In contrast, engineers can design solar panels following conventional reliability levels for rooftops, i.e., risk category II. Engineers can design them with even lower levels, i.e., risk category I, if the solar installation structural failure "represents low risk to human life in the event of failure" as for large ground-mounted installations in remote locations (Cain et al., 2015). Moreover, by design, the solar generators themselves must be placed outdoors and are directly exposed to extreme loads such as high winds. This exposure level is markedly different from existing generating units typically within protective infrastructure. For example, natural gas, source of $40 \%$ of the electricity in the United States (U.S. Energy

Corresponding author: L. Ceferino. Address: 370 Jay St, Room 1309, Brooklyn, NY 11201. Email: ceferino@nyu.edu 
Information Administration, 2021), is transported in pipes underground and is processed in power plants with several key equipment within buildings, protecting them from winds. As solar generation becomes a key source of our energy production, we need a better understanding of its resilience to natural hazards and its ability to provide sufficient and reliable power during extreme load conditions.

Fragility functions describe the likelihood of damage (or failure) due to an extreme load, e.g., earthquake shaking, hurricane wind. The development of fragility functions for energy generation components is essential to understand the risk profile of power systems (Bennett et al., 2021; Winkler et al., 2010; Zhai et al., 2021). However, lack of data has prevented the assessment of panel vulnerability to extreme loads, hindering our ability to understand the resilience of future power grids. Due to the lack of solar panel failure data or appropriate experimental tests, Goodman (2015) used simplified numerical structural assessment to propose the first solar panel fragility functions. The analysis focused on yielding onset of rooftop panel racks due to high wind loads. Due to the lack of better models, its fragility function has also been applied to ground-mounted solar panels (Bennett et al., 2021; Watson, 2018). To the best of the authors' knowledge, data-driven assessments of solar panel vulnerability have not been conducted.

In this paper, we fill this research gap by analyzing a novel dataset of solar panel structural performance in 60 sites in the Caribbean after the 2017 and 2019 hurricane seasons. This dataset captures these storms' severe impact on renewable infrastructure, especially in Puerto Rico (Kwasinski, 2018). We use this dataset to propose the first data-driven fragility curves for both rooftop and ground-mounted solar panels. Through a Bayesian approach, we supplement this empirical dataset with numerically driven fragility functions by Goodman (2015). Combining these different information sources results in more robust estimates of fragility function parameters than those based on either observation or numerical simulation. We present an algorithm based on Metropolis-Hastings (MH) Monte Carlo Markov Chain (MCMC) to solve the Bayesian update with computational efficiency. Additionally, the Bayesian approach explicitly characterizes the uncertainty in the fragility functions' parameters, which is critical to account for the uncertainty of key risk metrics, e.g., panels' annual rate of failure.

Next, this paper shows an application of the developed fragility functions by assessing the structural reliability of solar panels in Miami-Dade, Florida, to hurricanes. Our assessment combines our new fragility functions and hurricane hazard modeling for mainland United States (Marsooli et al., 2019). Finally, this paper explores the value of increasing solar panel strength to, for example, assess its effectiveness in reducing annual failure rates and meet different ASCE7-16 standards for structural reliability. This paper contributes to the body of literature on the risk of modern power systems to extreme events by providing the first data-informed fragility functions for solar panels and a holistic assessment of their reliability to hurricanes.

78

79

80

81

82

83

84

85

86

87

\section{SOLAR PANEL STRUCTURAL PERFORMANCE DATA}

\subsection{Panel damage data}

Our dataset is an extended version of the "Solar Under Storm" reports" panel failure dataset (Burgess et al., 2020; Burgess \& Goodman, 2018). The initial dataset consists of 26 sites primarily located in residential buildings in Puerto Rico for rooftop panels. "Solar Under Storm" focuses on reporting main failure mechanisms in rooftop installations with qualitative descriptions of failure modes in the Caribbean after the large hurricanes Irma and Maria in 2017 and Dorian in 2019. The study reports frequent failures in racks and the clips that attach the panel to the racks (Burgess et al., 2020). Unlike Goodman (2015), which covers the early serviceability damage state, i.e., yielding onset in racks, the identified damage conditions in the dataset introduce a damage state of structural collapse (Figure 1). 


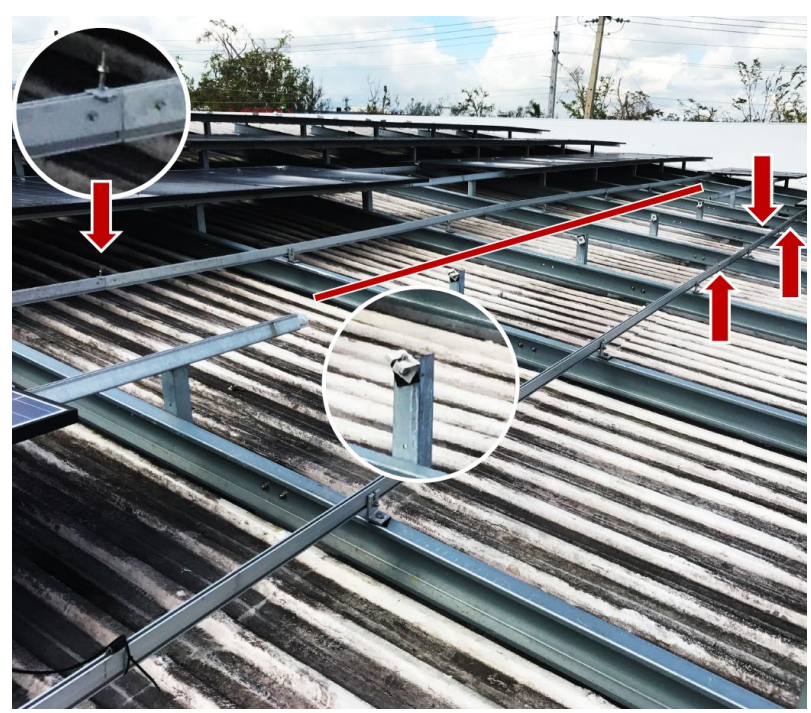

(a) Residential rooftop panels

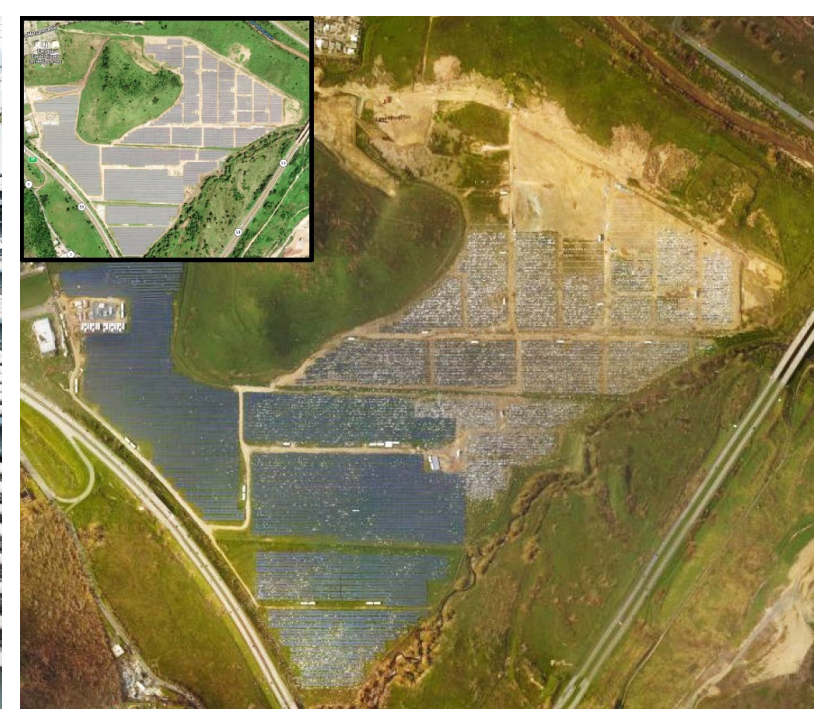

(b) Large ground-mounted panels

Figure 1. Example of solar panel damage in dataset. (a) Rooftop panels: Clip failures in the bolt connection between panels and racks (red arrows) lead to panel uplift (see bolts in circle with zoom-in view). Clamp failures (see rectangle with zoom-in view) lead to blown racks (see red line where a rack used to be placed) (Burgess et al., 2020). (b) Large ground-mounted panels: Satellite imagery shows the scale of the wind damage in comparison to the pre-hurricane view in the rectangle (National Oceanographic and Atmospheric Administration, 2021). In large-scale failures, multiple failure modes were found, including debris impact from damaged panel arrays.

Because the "Solar under Storm" dataset focuses on failed rooftop panels, we extended the dataset to cover panels that survived the hurricanes. The data extension is critical to properly fit fragility functions with data representing various panels' structural performance. By surveying local engineers in Puerto Rico, we extended the dataset to 46 sites. Supplementary Table 1 shows the list of the rooftop solar panels, their geographical coordinates, and their failure mode, e.g., Figure 1a. Out of the 46 sites, $46 \%$ experienced clip (clamp) failures, $17 \%$ racking failures, $4 \%$ roof attachment failures, and $50 \%$ either rack or connection or roof attachment failure. Most panels underwent damage due to debris impact (65\% in the initial dataset). It is important to note that debris failure was primarily part of a cascading mechanism with projectiles originating from the damaged panels themselves. Figure 2a shows a map with all the panel installation sites, indicating clip, racking, or attachment failures. The plot also shows that Hurricane Irma, Maria, and Dorian's tracks were near the sites.

For ground-mounted solar panels, we surveyed reports and newspapers to determine panels' failures in large sites. Utility-scale solar installations are primarily ground-mounted, each one composed of hundreds or thousands of panels. Thus, their failures often have media coverage. We visually verified the installation damage with high-resolution satellite imagery from the National Oceanic and Atmospheric Administration (NOAA) (National Oceanographic and Atmospheric Administration, 2021) and Google Earth Satellite Imagery. We obtained information for 14 large panel installations with $13 \mathrm{MW}$ of capacity on average in the Caribbean for Hurricanes Irma and Maria in 2017. The "Solar Under Storm" study also surveyed a few of these installations, but it did not report the installations' geographical coordinates to preserve the confidentiality of the sites (Burgess \& Goodman, 2018). Supplementary Table 2 shows the list of these ground-mounted solar panels, their geographical coordinates, capacity, and the percentage of failed panels (see site failure in Figure 1b). 36\% of sites reported significant failures in more than $50 \%$ of their panels, including the Humacao Solar Farm with 40 MW of capacity, the second largest solar farm in Puerto Rico (Institute for Energy Research, 2018). Figure 2b shows installations indicating the sites with significant failures, i.e., more than $50 \%$ of failed panels. The reported failures included clip (clamp) failures, racking 
fractures and buckling, bolt shear failure, and bolt loosening (Burgess \& Goodman, 2018). We observed evidence of cascading structural failures triggered by debris from damaged panels in large sites, suggesting that damage in a few panels can progress quickly to massive failures. This observation is consistent with the cascading failures of clip (T-clamps) fractures found in the more detailed post-hurricane structural inspections (Burgess \& Goodman, 2018).

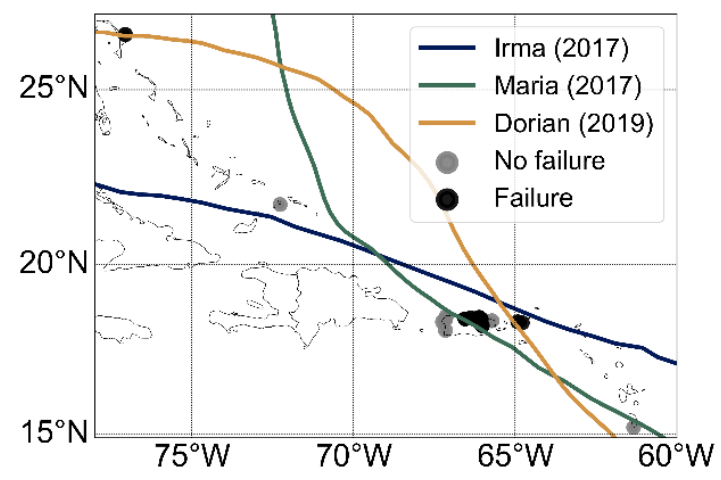

(a) Residential rooftop panels

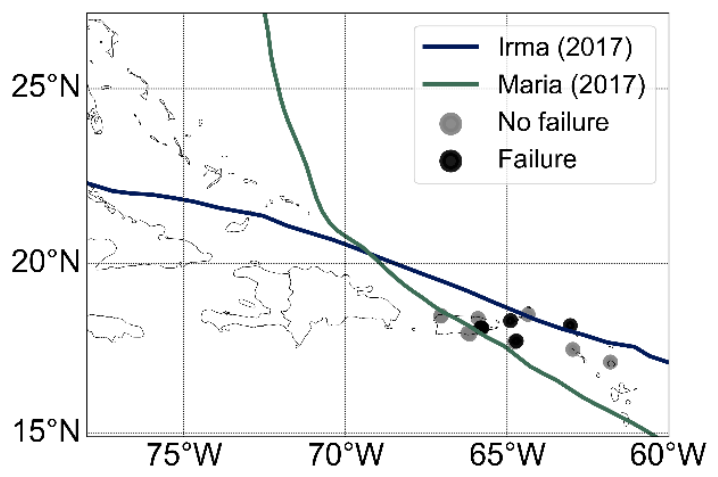

(b) Large ground-mounted panels

Figure 2. Solar panel sites in collected dataset after Hurricanes Irma and Maria in 2017 and Hurricane Dorian in 2019. The lines indicate the hurricane tracks, and the panels with failures (clip, racking, rooftop attachment) and without failures are highlighted in the map. Failure in the panel array is defined as either clip, racking, or roof attachment (in case of rooftop panels) failures in more than $50 \%$ of the panels.

In Puerto Rico, where 50\% and 59\% of the inspected rooftop and ground-mounted panels were located, wind design levels range from 63 to $72 \mathrm{~m} / \mathrm{s}$ and from 57 to $76 \mathrm{~m} / \mathrm{s}$ for structures with risk categories I and II, respectively (American Society of Civil Engineers, 2017). As mentioned earlier, the ASCE7-16 requires solar panels on residential buildings to be designed with a risk category of II. Ground-mounted solar panels can be designed with a risk category I since they "represent low risk to human life in the event of failure". While the structural design levels for ground-mounted solar panels are lower, our described findings reported fewer sites with large failures than rooftop panels (50\% versus $60 \%$ ). For further assessment, we analyzed the wind conditions that the panels experienced.

\subsection{Wind conditions}

We obtained the hurricanes' tracks, their radii of maximum wind, and maximum winds from the revised HURDAT2 Atlantic hurricane database (Landsea \& Franklin, 2013). We estimated axisymmetric winds circulating counterclockwise based on a tropical cyclone wind profile model (Chavas et al., 2015). We then combined these circulating winds with the estimated background winds (Lin et al., 2012) to calculate the resulting asymmetric wind fields for each hurricane. For smoothness, we interpolated HURDAT2 3-hour timesteps and thus the corresponding wind fields to obtain maximum wind at each panel site for every 10 minutes (Supplementary Figure 1).

For evaluation, we compared the resulting wind estimates to the hourly wind records from the NOAA National Centers for Environmental Information (2001)' Global Integrated Surface Dataset during Hurricane Maria from the weather station at the San Juan International Airport in Puerto Rico (Figure 3). No other stations reported wind data from Puerto Rico for the event. Unfortunately, wind data were not gathered for the most intense period; nevertheless, data during and before August 20th, 2017, show that our 
wind estimates and records closely follow each other. During August 20th, both datasets showed rapid wind intensification, at least up to the $\sim 30 \mathrm{~m} / \mathrm{s}$, when records stopped. Our estimates indicate that winds peaked at $60 \mathrm{~m} / \mathrm{s}$ on August 20 2017.

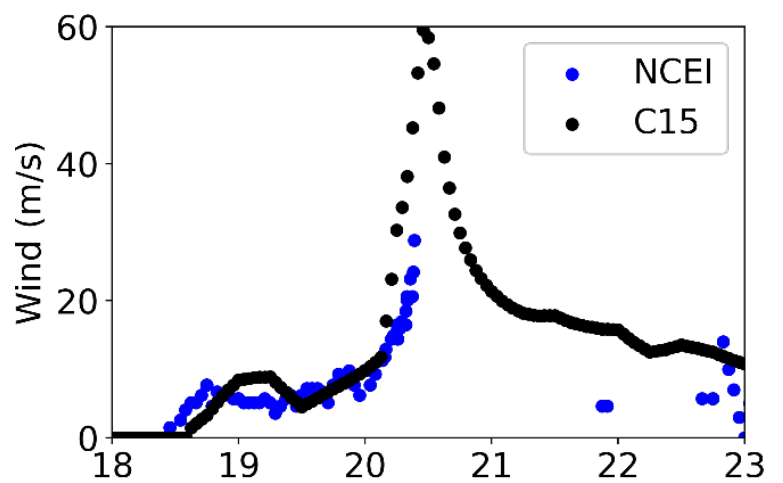

Figure 3. Comparison of wind estimates from Chavas et al. (2015), (C15), and the wind records from NOAA National Centers for Environmental Information (2001), (NCEI), at the San Juan International Airport.

Using a multiplicative factor from an empirical formula (Vickery \& Skerlj, 2005), we converted the 1-m sustained wind estimates at the panel sites to 3 -second gusts to be compatible with the wind load metrics for structural design (American Society of Civil Engineers (ASCE), 2017). Failures in rooftop panels were caused by gusts starting at $73 \mathrm{~m} / \mathrm{s}$, with a mean in all sites of $81 \mathrm{~m} / \mathrm{s}$ (Figure 4a). Failures in ground-mounted panels were caused by gusts starting at $83 \mathrm{~m} / \mathrm{s}$, with a mean of $91 \mathrm{~m} / \mathrm{s}$ (Figure $4 \mathrm{~b}$ ). The solar panel dataset is suitable for assessing fragility functions as it contains ranges of gusts where failure occurrence has large variability (Figure 4). For example, between 70 and $90 \mathrm{~m} / \mathrm{s}$, several sites with rooftop panels experienced both failure and no failure. Getting data in this range is critical for fragility functions to appropriately capture the uncertainties in panel failure when transitioning from low winds to high winds.

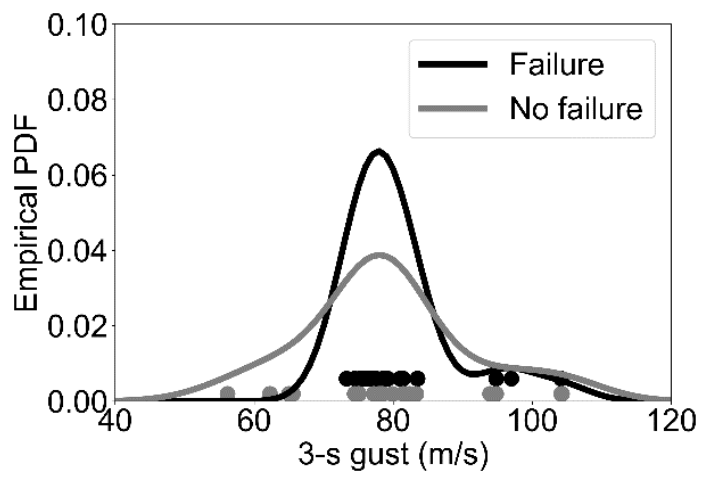

(a) Rooftop panel

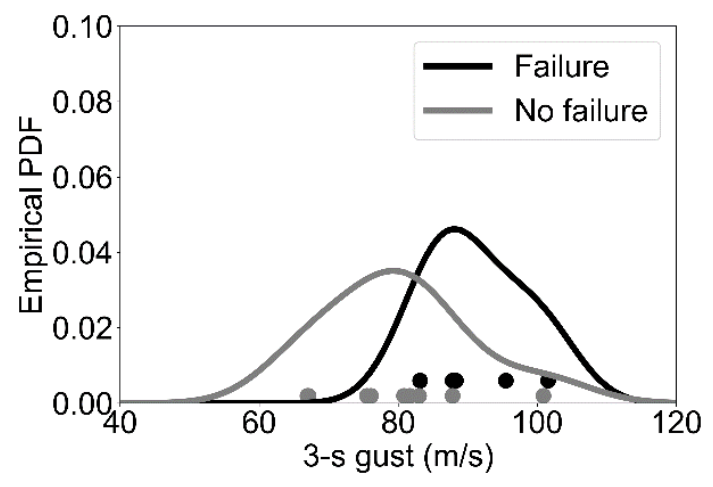

(b) Ground-mounted panel

Figure 4. 3-s gust distributions for panels with (black) and without (gray) damage. The data are shown as points and the empirical probability density functions are estimated using a Gaussian kernel

\section{BAYESIAN FRAMEWORK FOR FRAGILITY FUNCTION UPDATES}

\subsection{Fragility function}


Fragility functions with lognormal shape are typically used to model infrastructure's damage due to wind hazards and multiple other extreme loads (Ellingwood et al., 2004; Shinozuka et al., 2000; Straub \& der Kiureghian, 2008). Its shape is given by

$$
q(w ; v, \beta)=\Phi\left(\frac{\ln (w)-\ln (v)}{\beta}\right)
$$

where $q$ is the probability of panel failure due to a wind gust $w, v$ is the wind gust with a failure probability of $50 \%, \beta$ is a normalizing factor, and $\Phi$ is the cumulative standard normal distribution function. $\beta$ defines the width of the transition range between winds with low and high failure probability, and it is a measure of aleatory uncertainty in the vulnerability analysis. For example, a $\beta$ value of 0 would be equivalent to a deterministic assessment, where the panel would fail after a given wind threshold.

We follow a Bayesian approach to fit solar panels' fragility functions due to two key factors.

- The Bayesian formulation can represent fragility functions' significant epistemic uncertainties through random fragility function parameters, $v$ and $\beta$. Treating $v$ and $\beta$ as random variables rather than deterministic parameters allows for the propagation of their uncertainty to solar panel damage predictions in risk analysis.

- The Bayesian approach allows for the combination of multiple sources of information to improve the fragility function characterization. The dataset presented in this paper provides the opportunity for a data-driven, probabilistic description of panel failure. However, the number of samples is not high, e.g., 46 and 14 for rooftop and ground-mounted panels, respectively. Thus, through the Bayesian approach, we use Goodman (2015)'s numerical assessment as prior information and then combine it with the dataset for the final fragility function estimates.

In the Bayesian formulation, the posterior distribution $p(v, \beta \mid x)$ after combining both data sources is

$$
p(v, \beta \mid x)=\frac{p(x \mid v, \beta) p(v, \beta)}{\iint p(x \mid v, \beta) p(v, \beta) \operatorname{dvd} \beta}
$$

where $x=\left\{x_{1}, x_{2}, \ldots, x_{n}\right\}$ is the vector containing the failure information at each site, thus $x_{n} \in\{0,1\}$ equals zero if the panel did not fail and one if it failed, and $n$ is the number of sites, i.e., equal to 46 and 14 for rooftop and ground-mounted panels, respectively. The limit state for rooftop panel failure is defined as extensive damage, including clip, racking, or roof attachment failures. Hereafter, we refer to this damage state as panel failure. The limit state for failure in the large ground-mounted panels is defined as extensive damage, including clip and racking failures, in more than $50 \%$ of their panels. $p(x \mid v, \beta)$ is the likelihood function of observing the dataset for fixed values of $v$ and $\beta$, and $p(v, \beta)$ is the prior distribution of $v$ and $\beta$.

\subsection{Prior}

As in the Bayesian approach, $v$ and $\beta$ from Equation (2) are random variables rather than deterministic values. Additionally, $v$ and $\beta$ can only be positive numbers. Accordingly, we use lognormal distributions to model the prior. The probability density functions (pdfs) of $p(v)$ and $p(\beta)$ are given by

$$
\begin{aligned}
& p(v)=\frac{1}{v \sigma_{v} \sqrt{2 \pi}} \exp \left(-\frac{\left(\ln v-\mu_{v}\right)^{2}}{2 \sigma_{v}^{2}}\right) \\
& p(\beta)=\frac{1}{\beta \sigma_{\beta} \sqrt{2 \pi}} \exp \left(-\frac{\left(\ln \beta-\mu_{\beta}\right)^{2}}{2 \sigma_{\beta}^{2}}\right)
\end{aligned}
$$

where $\mu_{v}$ and $\sigma_{v}$ are hyperparameters defining the logarithmic mean and standard deviation of $v . \mu_{\beta}$ and $\sigma_{\beta}$ are hyperparameters defining the logarithmic mean and standard deviation of $\beta$. For simplicity, we assume $v$ and $\beta$ are independent. Thus

$$
p(v, \beta)=p(v) p(\beta)
$$


For Bayesian assessments, the data supporting the prior distribution need to be independent of the data used for the parameter update. Thus, the selection of Goodman (2015)'s fragility function is appropriate for this study. The numerical assessment is based on code-conforming rooftop panels designed for wind conditions in Atlanta, Georgia. The uncertainty in the fragility function stems from the stochastic velocity pressure induced by winds acting on the panel. It also models stochasticity in material strength and construction quality. Goodman (2015)'s study is frequentist; thus, the parameters defining the fragility function in Equation (1) are deterministic. The resulting fragility functions had a deterministic $v$, gust for $50 \%$-failure probability, of $60 \mathrm{~m} / \mathrm{s}$ and $\beta$ of 0.13 for a panel on a $30^{\circ}$ roof.

To use these numerical evaluations as a prior distribution, we adjusted their wind design conditions to the Caribbean. Taking San Juan, Puerto Rico, as a reference, we scaled up $v$ to represent a local solar panel design using the ratio between the wind design values in San Juan and Atlanta. We consider a design with risk category II (wind with a return period of 700 years) for rooftop panels and a risk category I (wind with a return period of 300 years) for the ground-mounted panels (Cain et al., 2015). As a result, we used $v$ equal to $85 \mathrm{~m} / \mathrm{s}$ for rooftop panels and $81 \mathrm{~m} / \mathrm{s}$ for ground-mounted panels.

We use the values of $85 \mathrm{~m} / \mathrm{s}$ and $81 \mathrm{~m} / \mathrm{s}$ to find the prior logarithmic means of $v\left(\mu_{v}\right)$ for the rooftop and ground-mounted solar panels, respectively, since they are equal to the prior medians $\left(e^{\mu_{v}}\right)$ in the lognormal distributions. For the logarithmic means of $\beta\left(\mu_{\beta}\right)$, we use Goodman (2015)'s value of 0.13 for both panel types. The logarithmic standard deviations $\left(\sigma_{v}\right.$ and $\left.\sigma_{\beta}\right)$ are a measure of epistemic uncertainty as data can reduce them. We consider the results from Goodman (2015)'s numerical assessment to be initial sound data. Thus, we use it as an informative prior rather than using weakly informative or non-informative prior (Gelman et al., 2013). Accordingly, we set $\sigma_{v}$ and $\sigma_{\beta}$ equal to 0.5 . This value is similar to other Bayesian assessments for vulnerability curves (Noh et al., 2017), and it accounts for the lack of information (e.g., actual material strength or failure modes) in the numerical study in reproducing panel failure.

\subsection{Likelihood of observing the data}

Panel failure follows a Bernoulli distribution with probability $q$ that is a function of the wind. Considering that the failures at different $n$ sites are independent, then the likelihood of observing failures or non-failures in $n$ sites is given by

$$
p(x \mid v, \beta)=\prod_{i=1}^{n} q^{x_{i}}(1-q)^{1-x_{i}}
$$

where $x_{i}$ is one if the panel failed at the site or zero otherwise and $q$ is found from the fragility function in Equation (1) with parameters $v$ and $\beta$.

\subsection{Posterior distribution}

According to the Bayes rule for conditional probabilities, the posterior $p(v, \beta \mid x)$ can be found in Equation (2). The numerator is the product of the likelihood of observing the panel failures and the prior distribution. The denominator is the integral of this product through the entire parameter space of $v$ and $\beta$. Equations (5) and (6) allow us to find the numerator in closed form, but the denominator requires a complex integration that cannot be solved analytically.

\subsection{Solving for the posterior distribution using MCMC}

To overcome the challenge stemming from numerical integration, we followed an approach based on MCMC (Liu, 2004). MCMC only requires evaluating a proportional function to the posterior distribution rather than the posterior itself. Thus, we can find samples from the posterior and circumvent the evaluation of the integral with MCMC since 


$$
p(v, \beta \mid x) \propto p(x \mid v, \beta) p(v, \beta)
$$

We use the Metropolis-Hastings (MH) MCMC algorithm to define a Markov Chain (MC) that samples from the posterior distributions of $v$ and $\beta$. With the $\mathrm{MH}$ algorithm, we define the MC as a random walk through the parameter space of $v$ and $\beta$. To generate $m$-th sample pair $\left(v_{m}, \beta_{m}\right)$ of the posterior, we sample a candidate $\left(v^{*}, \beta^{*}\right)$ using the following uncorrelated bivariate normal distribution

$$
\left(v^{*}, \beta^{*}\right) \sim N\left(\boldsymbol{\mu}_{(R W)}, \boldsymbol{\sigma}_{(R W)}\right)
$$

where $\boldsymbol{\mu}_{(\boldsymbol{R} W)}$ is the mean vector of the random walk, and it is equal to the last posterior sample $\left(v_{m-1}, \beta_{m-1}\right) . \sigma_{(R W)}$ is the covariance matrix, equal to the diagonal matrix $\operatorname{diag}\left(\sigma_{v(R W)}, \sigma_{\beta(R W)}\right) . \sigma_{v(R W)}$ and $\sigma_{\beta(R W)}$ are calibrated values for an effective exploration of the high-probability regions, i.e., good mixing. For this symmetrical random walk, the sample candidate $\left(v^{*}, \beta^{*}\right)$ is accepted with probability $\min (1, A)$, where

$$
A=\frac{p\left(x \mid v^{*}, \beta^{*}\right) p\left(v^{*}, \beta^{*}\right)}{p\left(x \mid v_{m-1}, \beta_{m-1}\right) p\left(v_{m-1}, \beta_{m-1}\right)}
$$

According to the $\mathrm{MH}$ properties, the $\mathrm{MC}$ has a stationary distribution, i.e., the resulting distribution when the number of samples is sufficiently large, equal to the posterior distribution of $v$ and $\beta$ in Equation (2).

This algorithm was implemented to assess the posterior of the fragility function parameters for both rooftop and ground-mounted panels. We ensured a good mixing by calibrating $\sigma_{v(M C M C)}$ and $\sigma_{\beta(R W)}$ such that the average acceptance rate is around $25 \%$ as recommended in the literature (Chib \& Greenberg, 1995; Robert, 2014). Using the MH MCMC analysis, we sampled 10,000 realizations of $v$ and $\beta$ from the posterior distribution after a burn-in period containing 1,000 realizations. We selected the burn-in period after verifying the MC stationarity (Supplementary Figure 2).

\section{BAYESIAN UPDATES FOR FRAGILITY FUNCTIONS}

\subsection{Rooftop panels}

We used the generated 10,000 samples to estimate the posterior distribution of the fragility function parameters. For $v$, the median varied from $85 \mathrm{~m} / \mathrm{s}$ in the prior to $80 \mathrm{~m} / \mathrm{s}$ in the posterior, its standard deviation from $51 \mathrm{~m} / \mathrm{s}$ to $5 \mathrm{~m} / \mathrm{s}$, and its logarithmic standard deviation from 0.5 to 0.07 (Figure $5 \mathrm{a}$ ). The similar prior and posterior medians show that the numerical analysis in Goodman (2015) is consistent with the observations of wind in terms of the $50 \%$-failure probability. The significant decrease $(90 \%)$ in the standard deviation reveals the importance of the solar panel dataset in decreasing the initial epistemic uncertainties of $v$.

For $\beta$, the median varied from 0.13 in the prior to 0.32 in the posterior, its standard deviation from 0.08 to 0.11 , and its logarithmic standard deviation from 0.5 to 0.30 (Figure $5 \mathrm{~b}$ ). The posterior median of $\beta$ is almost three times the prior value. Such an increase reveals the inconsistency of the numerical analysis in Goodman (2015) with the empirical data in terms of the aleatory uncertainty measured by $\beta$. The numerical analysis implies that the transition range between winds with low and high failure probabilities is narrow. Conversely, previous empirical evidence (Roueche et al., 2017, 2018) suggests that the $\beta$ value of 0.13 is too small to characterize the uncertainty in wind hazards, implying a wider transition range between winds with low and high failure probabilities. This observation demonstrates the importance of empirical data to calibrate numerical analysis.

We found a lack of correlation between $v$ and $\beta$ in the posterior as the Pearson's coefficient between their posterior samples was only $3 \times 10^{-4}$. This result suggests independence between $v$ and $\beta$, as assumed in the prior. 
The Bayesian update from the parameters' prior distribution to the posterior distribution brings important implications for the fragility function of rooftop solar panels. The mean fragility function, describing the probability of panel failure, for the posterior distribution can be found as

$$
E[q(w)]=\int_{0}^{\infty} \int_{0}^{\infty} q(w ; v, \beta) p(v, \beta \mid x) d v d \beta
$$
Equation (10) uses the posterior $p(v, \beta \mid x)$ as the distribution of $v$ and $\beta$ to find the posterior of $E[q(w)]$. Replacing $p(v, \beta \mid x)$ by the prior $p(v, \beta)$ will result in the prior $E[q(w)]$.

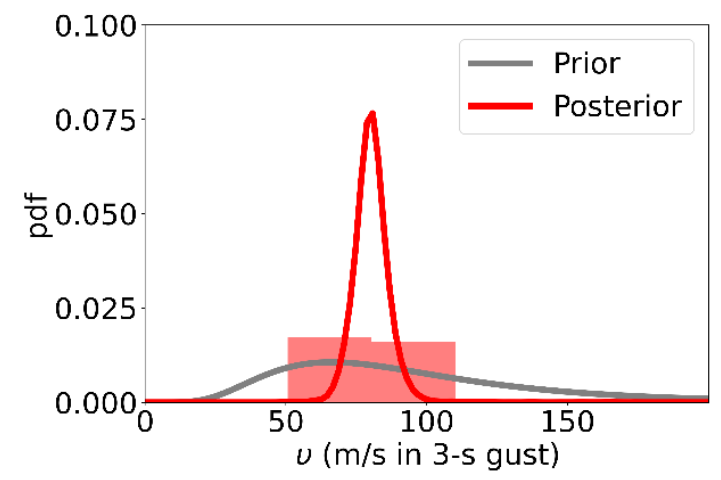

a) $v$ (rooftop panel)

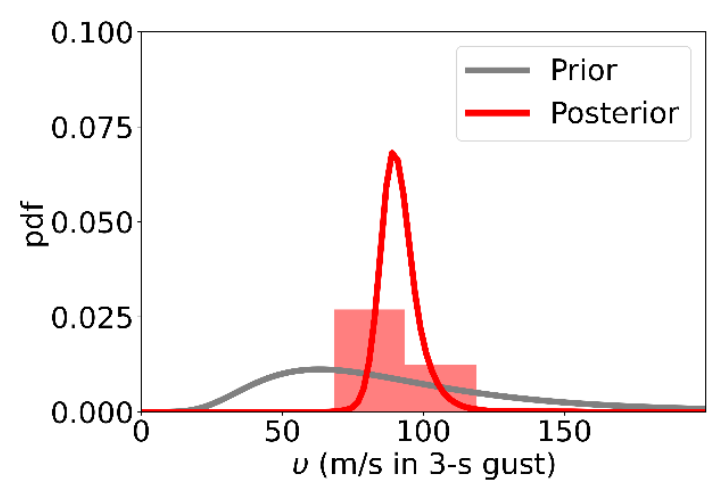

c) $v$ (ground-mounted panel)

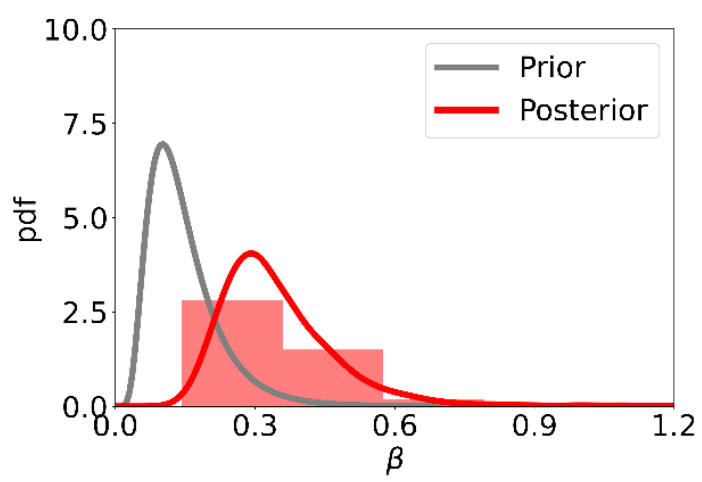

b) $\beta$ (rooftop panel)

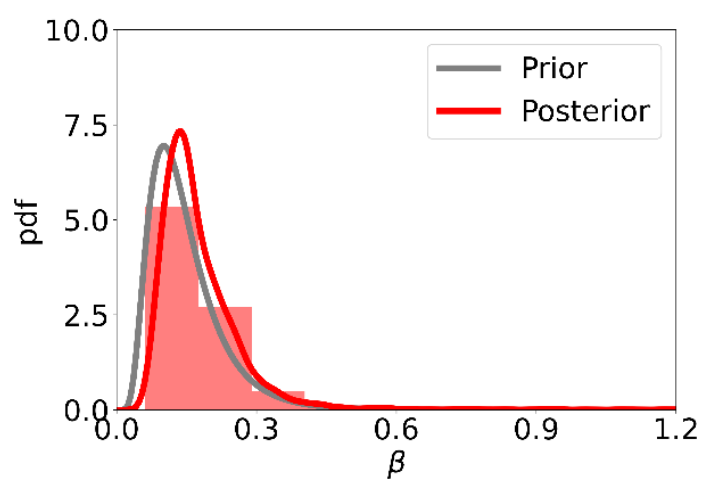

d) $\beta$ (ground-mounted panel)

Figure 5. The prior and posterior distribution of $v$ and $\beta$ for rooftop solar panels. Samples from the posterior distribution were used to depict the histogram, and Gaussian kernel was used to develop each empirical pdf.

271

We solved Equation (10) by averaging all $q$ values for the suite of 10,000 fragility functions, obtained by evaluating the 10,000 samples of $v$ and $\beta$ (Figure 6a). With this procedure, we incorporate and propagate the uncertainty in $v$ and $\beta$ to the fragility function. The deterministic prior distribution in Goodman (2015) was used to set up the prior medians' hyperparameters. However, the resulting mean fragility function $(E[q(w)])$ from the Bayesian prior is different than its frequentist counterpart due to its parameters' uncertain nature. The difference is negligible for the wind with a $50 \%$-failure probability $(\sim 85 \mathrm{~m} / \mathrm{s}$ for both). Yet, it is significant for the wind with a 10\% and 90\%-failure probability (71 versus 43 and 100 versus 167 $\mathrm{m} / \mathrm{s}$ ). The wider wind range in the transition from a $10 \%$ to a $90 \%$-failure probability in the Bayesian assessment results from the uncertainty propagation from $v$ and $\beta$ (Figure 5a and 5b's grey curves) to the fragility function. 
The posterior distribution changes the wind for 50\%-failure probability only slightly (-5\%), from $86 \mathrm{~m} / \mathrm{s}$ in the prior to $80 \mathrm{~m} / \mathrm{s}$ in the posterior. The wind range that transitions from a $10 \%$ to a $90 \%$-failure probability, 52 and $123 \mathrm{~m} / \mathrm{s}$, respectively, has a width that is $56 \%$ smaller than the prior. This reduction results from the lower uncertainty on $v$, whose standard deviation decreases from $51 \mathrm{~m} / \mathrm{s}$ in the prior to $5 \mathrm{~m} / \mathrm{s}$ in the posterior (Figure 5a). Moreover, the posterior fragility function shows a significantly narrower confidence interval than the prior fragility function. These results demonstrate the importance of the Bayesian approach to capture and reduce large initial uncertainties through empirical data, not only in the fragility function parameters $(v$ and $\beta)$, but also in the mean fragility function itself.

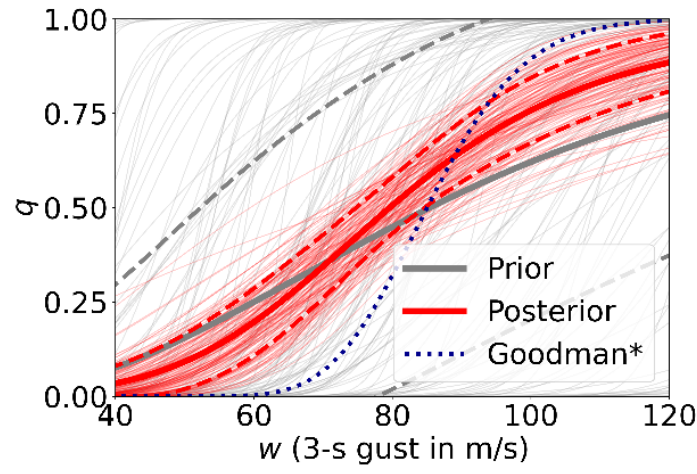

a) Rooftop panel

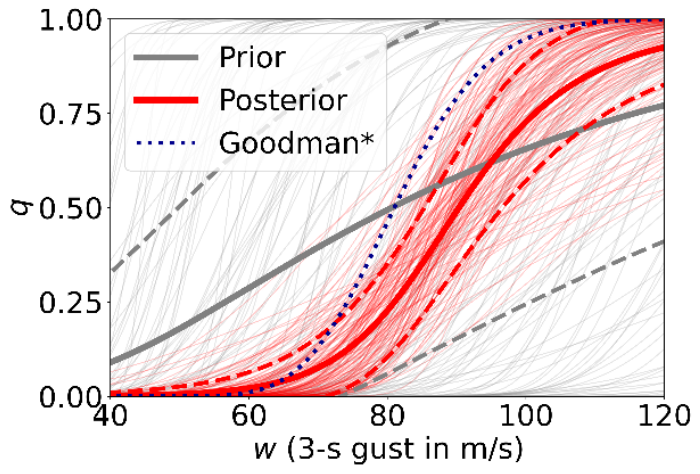

b) Ground-mounted panel

Figure 6. Fragility functions for random samples $v$ and $\beta$ according to their prior and posterior distributions. The solid thicker lines indicate the expectation of the failure probability over the parameters' distribution, and the dashed lines indicate the mean plus and minus a standard deviation. Goodman* is the deterministic fragility function adapted from Goodman (2015).

\subsection{Ground-mounted panels}

The distribution of $v$ shows that the median varies from $81 \mathrm{~m} / \mathrm{s}$ in the prior to $90 \mathrm{~m} / \mathrm{s}$ in the posterior, its standard deviation from $50 \mathrm{~m} / \mathrm{s}$ to $6 \mathrm{~m} / \mathrm{s}$, and its logarithmic standard deviation from 0.5 to 0.07 (Figure $5 \mathrm{c})$. The posterior shows a significant reduction in the uncertainty of $v$, with a standard deviation $87 \%$ lower than that of the prior. Such a reduction is very close to the one found in rooftop solar panels, even though the number of data points is one-third of the latter.

For $\beta$, the median varies from 0.13 in the prior to 0.15 in the posterior, its standard deviation remains in 0.07 , and its logarithmic standard deviation from 0.5 to 0.39 (Figure $5 \mathrm{~d}$ ). As a result, the posterior distribution exhibits a slight shift to the right. The little variations in $\beta$ 's standard deviation and logarithmic standard deviation suggest that the number of data points is insufficient to substantially reduce uncertainty.

Following the same procedure for the rooftop panels, we estimated the mean fragility function $(E[q(w)])$ for ground-mounted solar panels (Figure $6 \mathrm{~b}$ ). Unlike the posterior fragility function for rooftop panels, the posterior fragility function for ground-mounted panels has a higher wind value $(+10 \%)$ for a $50 \%$-failure probability than its prior, $90 \mathrm{~m} / \mathrm{s}$ versus $81 \mathrm{~m} / \mathrm{s}$. This increase suggests that the panel installations for groundmounted solar panels were structurally sounder than for rooftop panels, whose wind for $50 \%$-failure probability in the posterior was $5 \%$ less than in the prior. This better structural performance may result from more code enforcement, better member and connection installation (e.g., avoiding loose bolts), or proper inspections (Burgess et al., 2020; Burgess \& Goodman, 2018). These panels are part of large installations with massive investments from utility companies, which, unlike residential homes that install rooftop panels, often have a budget for appropriate quality and control. 
We found that the wind range that transitions from a $10 \%$ to $90 \%$ failure probability in the posterior, 73 and $116 \mathrm{~m} / \mathrm{s}$, is reduced in $64 \%$ from the prior, $41 \mathrm{~m} / \mathrm{s}$ and $160 \mathrm{~m} / \mathrm{s}$. This narrower range is driven mainly by the lower standard deviation in $v$ (Figure 5c). This reduction in the transition range is larger than that in the case of the rooftop panels (Figure 6) because, unlike the rooftop panels, the ground-mounted panels' posterior of $\beta$ did not have a larger standard deviation than the prior. Furthermore, the posterior fragility function shows a much narrower confidence interval than the prior fragility function. However, the confidence interval is slightly wider than in rooftop panels because the ground-mounted panel dataset is only a third of the rooftop panel dataset.

\section{PANEL'S ANNUAL FAILURE RATE}

To illustrate their application, we use our fragility functions to assess solar panel risk for hurricane winds for Miami-Dade, Florida, as a case study. Miami-Dade is exposed to similar wind hazards in Puerto Rico. For example, the risk category II design wind (700-year return period) in San Juan, Puerto Rico, is $71 \mathrm{~m} / \mathrm{s}$ $(159 \mathrm{mph})$, whereas the design wind in Miami-Dade is $73 \mathrm{~m} / \mathrm{s}(164 \mathrm{mph})$. Different standards for solar panel installation and code enforcement might be in place in Miami-Dade, especially for rooftop panels, which performed worse than ground-mounted panels. However, more data collection efforts will be needed to confirm whether panels in mainland United States have fundamentally different structural behavior than those in the Caribbean. Due to the lack of these datasets, here we use our fragility functions from the Caribbean to study solar panels' reliability and resilience performance in Miami-Dade; analysis for other regions can be similarly performed.

A study site in the mainland United States is chosen to leverage a synthetic hurricane database with 5018 landfalling storms in the United States generated from a statistical-deterministic tropical cyclone (TC) model (Marsooli et al., 2019). These synthetic hurricanes account for current climate conditions (from 1980 to 2005) according to the National Center for Environmental Prediction (NCEP) reanalysis. The 5018 synthetic storms correspond to $\sim 1485$ years of storm simulation. The model that generates these storms consists of three stages: a genesis model; a beta-advection TC motion model; and a dynamical TC model that captures how environmental factors influence TC development (Emanuel et al., 2008). The model solves the synthetic storms' tracks, maximum sustained winds, and radii of maximum winds, and we use its results at 2-hour intervals. We estimated the wind fields by combining the storm's axisymmetric winds circulating counterclockwise (Chavas et al., 2015) and background winds (Lin et al., 2012). The synthetic hurricanes were evaluated with observations by Marsooli et al. (2019).

We determine the annual rate of panel failure $\lambda_{f}$ by combining the wind simulations with the Bayesian fragility functions. The rate defines the average number of events leading to panel failures in a given year assuming a Poisson process. In a frequentist analysis, the fragility function parameters $v$ and $\beta$ are fixed. Thus, $\lambda_{f}(v, \beta)$ can be estimated as

$$
\lambda_{f}(v, \beta)=\int_{0}^{\infty} q(w ; v, \beta) d \lambda_{w}
$$

where $\lambda_{w}$ is the annual exceedance probability of wind speed. It is the average number of events that result in winds exceeding a threshold $w$ in a given year under a Poisson process of storm arrivals, and it can be estimated from the synthetic storms. In our Bayesian framework, $v$ and $\beta$ are random variables. Thus, $\lambda_{f}$ is also a random variable. Accordingly, its probability density function $\mathrm{p}_{\lambda_{f}}(\lambda)$ can be found as

$$
\mathrm{p}_{\lambda_{f}}(\lambda)=\int_{0}^{\infty} \int_{0}^{\infty} p(v, \beta \mid x) \delta\left(\lambda-\int_{0}^{\infty} q(w ; v, \beta) d \lambda_{w}\right) d v d \beta
$$

where $\delta()$ is the Dirac delta function on $\lambda-\int_{0}^{\infty} q(w ; v, \beta) d \lambda_{\mathrm{w}}$. Equation (12) uses the posterior $p(v, \beta \mid x)$ as the distribution of $v$ and $\beta$ to find the posterior of $\mathrm{p}_{\lambda_{f}}(\lambda)$. Replacing $p(v, \beta \mid x)$ by the prior $p(v, \beta)$ will result in the prior $\mathrm{p}_{\lambda_{f}}(\lambda)$. The expected value of $\lambda_{f}, \mathrm{E}\left[\lambda_{f}\right]$, can be found as: 


$$
\mathrm{E}\left[\lambda_{f}\right]=\int_{0}^{\infty} \int_{0}^{\infty}\left[\int_{0}^{\infty} q(w ; v, \beta) d \lambda_{\mathrm{w}}\right] p(v, \beta \mid x) d v d \beta
$$

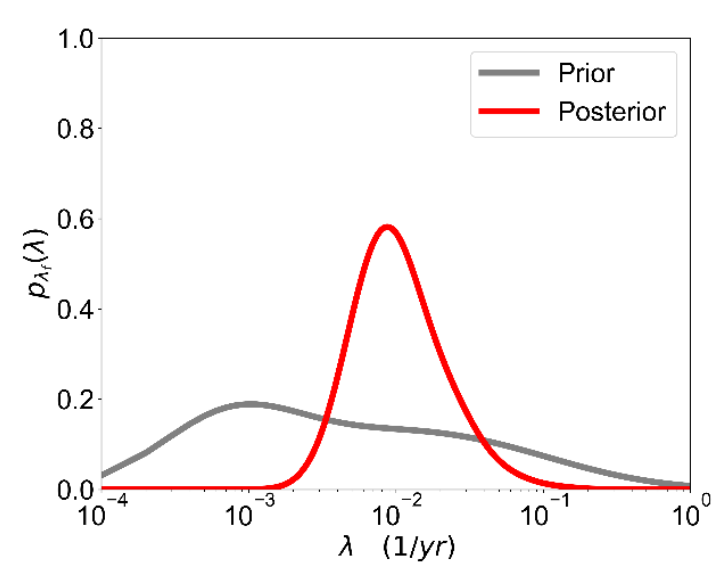

a) Rooftop panel of $\lambda_{f}$ (Figure 7).

Explicitly evaluating $\mathrm{E}\left[\lambda_{f}\right]$ and particularly $\mathrm{p}_{\lambda_{f}}(\lambda)$ is computationally challenging by traditional numerical integration. Thus, we used Monte Carlo analysis due to its simplicity to find such estimates. Using the 10,000 Monte Carlo samples of prior and posterior fragility functions, we estimated the prior and posterior

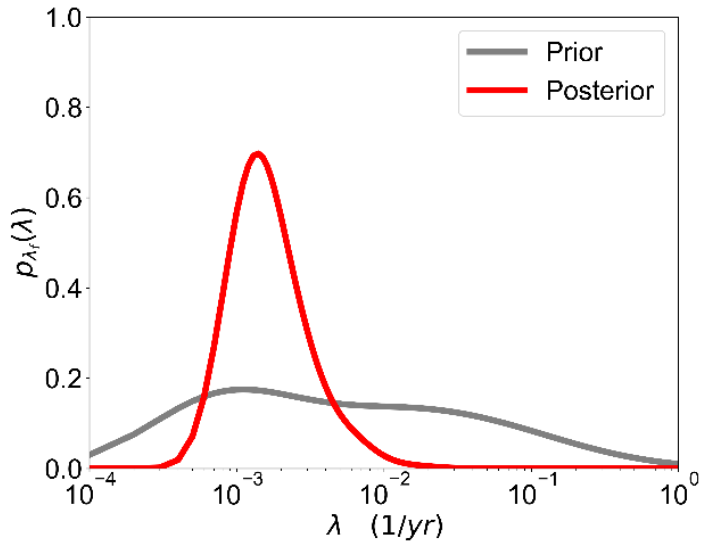

b) Ground-mounted panel
Figure 7. Probability density function $\mathrm{p}_{\lambda_{f}}(\lambda)$ of the annual probability of failure rate of solar panels. Samples from the Monte Carlo simulations were used to fit empirical pdfs with a Gaussian kernel.

Our results indicate a marked decrease in uncertainty for $\lambda_{f}$ in the posterior. The posterior standard deviation and logarithmic standard deviation for rooftop panels are $1.2 \times 10^{-2} / \mathrm{yr}$ and $6.3 \times 10^{-1}$, whereas the priors' ones are $5.1 \times 10^{-2} / \mathrm{yr}$ and 1.82 . The posterior standard deviation and logarithmic standard deviation for ground-mounted panels are $1.7 \times 10^{-3} / \mathrm{yr}$ and $5.5 \times 10^{-1}$, whereas the priors' ones are $5.7 \times 10^{-2} / \mathrm{yr}$ and 1.87 . This uncertainty decrease in the annual failure rate is consistent with the observed posterior fragility function uncertainty reductions for rooftop and ground-mounted panels (Figure $6)$.

For rooftop panels, the posterior $\mathrm{E}\left[\lambda_{f}\right]$ is $1.3 \times 10^{-2} / y r$, i.e., return period of 75 years. Under the assumption of a Poisson process, this rate results in a $48 \%$ probability of failure in 50 years. This rate is equivalent to a $33 \%$ failure probability in 30 years, often considered the usable panel service time. The reliability index, defined as the inverse of the cumulative standard normal distribution function on the survival probability, i.e., one minus the failure probability, in 50 years, is 0.04 . This reliability is significantly lower than the current standards in the ASCE7-16. Using results from a recent study (McAllister et al., 2018), we estimated that a structure designed for winds with a 700 -year return period (risk category II) should have a reliability index of 2.3 in 50 years, i.e., failure rate of $2.3 \times 10^{-4} / y r$. Thus, our findings show that the structural reliability of rooftop solar panels in our dataset was significantly below current code standards if similar panels are adopted in Miami-Dade. These results are consistent with the observed structural deficiencies in the installation and design of panels with failures in the dataset, e.g., insufficient connection strength, lack of vibration-resistant connections (Burgess et al., 2020). Thus, significant gains in reliability could be achieved by increasing quality and control during design and installation. 
For ground-mounted panels, the posterior $\mathrm{E}\left[\lambda_{f}\right]$ is $2.0 \times 10^{-3} / y r$, i.e., return period of 504 years. This rate is equivalent to a $9 \%$ and a $6 \%$ probability of failure in 50 and 30 years, respectively. The reliability index for 50 years is 1.3 . According to the ASCE7-16, the reliability index for a structure designed for winds with a 300-year return period (risk category I) is 1.9, i.e., failure rate of $6.1 \times 10^{-4} / y r$ (McAllister et al., 2018). Thus, our results indicate that ground-mounted panels also have lower reliability than required by the current code standards. These results are also consistent with previously reported structural deficiencies in ground-mounted panels in the Caribbean, e.g., undersized racks, and undersized or under-torqued bolts (Burgess \& Goodman, 2018). Nevertheless, the contrast between rooftop and ground-mounted panel performance indicates that the latter had a significantly higher structural reliability than the former.

\section{STRONGER SOLAR PANELS FOR GENERATION RESILIENCE}

\subsection{Assessing structural reliability and generation in stronger panels}

We assessed panels' strength increases by factors of 1.25, 1.50, 1.75, and 2.0. This wide range of strength increases accounts for addressing various panel installations and design deficiencies reported in the Caribbean. Existing studies already point to cost-effective solutions to correct these deficiencies, e.g., torque checks on bolts, well-designed clips (Burgess et al., 2020; Burgess \& Goodman, 2018).

This range also covers increases in strength for critical infrastructure. Hospitals and fire stations require that their buildings' structural and non-structural components have higher strength for continuous operations in a disaster emergency response. Accordingly, solar panels serving these facilities must be designed with a risk category IV, higher than for panels on residential (risk category II) or utility-scale (risk category I) installations. For example, the wind design in Miami-Dade is $69 \mathrm{~m} / \mathrm{s}$ (154 mph) for a risk category I and $81 \mathrm{~m} / \mathrm{s}(182 \mathrm{mph})$ for a risk category IV. The difference represents a strength factor of 1.40 as the design force is proportional to the square of the design wind.

For our assessment, we multiplied the posterior samples of $v$ by the square root of the strength increase factors, i.e., $1.12,1.22,1.32,1.41$. We let samples $\beta$ remain the same to limit the increase in uncertainty, i.e., the transition from low-failure-probability to high-failure-probability winds. The resulting fragility functions are shifted to the right of the posterior functions in Figure 6, reducing the likelihood of panel failure (Figure 8). For example, the mean failure probability $q$ when rooftop panels undergo gusts of 60 $\mathrm{m} / \mathrm{s}$ decreases from 0.19 to $0.12,0.08,0.05$, and 0.04 for the strength factors of $1.25,1.50,1.75$, and 2.0, respectively. Similarly, the mean $q$ when ground-mounted panels undergo gusts of $80 \mathrm{~m} / \mathrm{s}$ decreases from 0.23 to $0.09,0.04,0.02$, and 0.01 . 


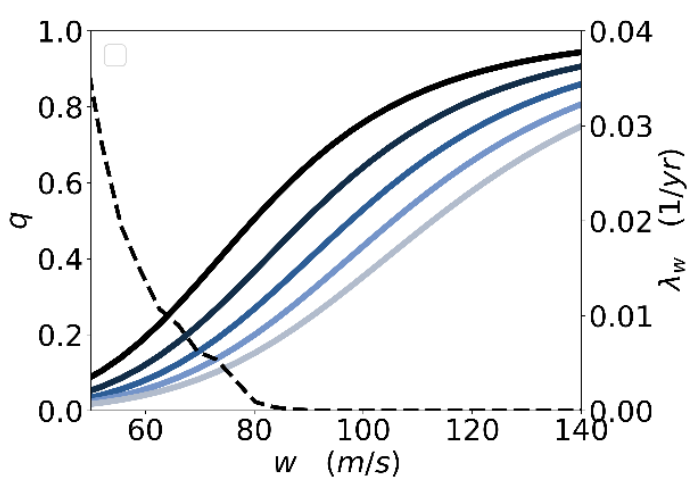

a) Rooftop panel

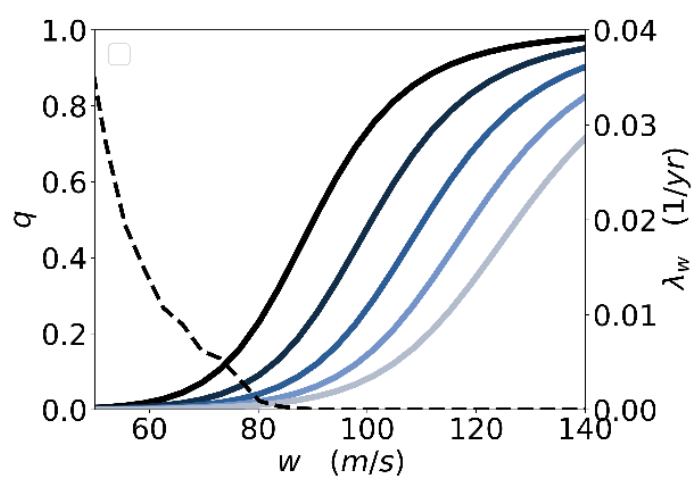

b) Ground-mounted panel

Figure 8. Mean fragility functions for panels with increases in strength. The factors that multiply each $v$ sample are equal to the square root of the strength factors in the labels. The dashed curves indicate the wind annual exceedance rates. The $x$-axis represents 3-s gusts.

Using Monte Carlo sampling, we estimated $\mathrm{p}_{\lambda_{f}}(\lambda)$ for the different increases in strength (Figure 9). Expectedly, increases in strength shift $\mathrm{p}_{\lambda_{f}}(\lambda)$ to the left as they reduce the resulting annual rate of failure. We also found $\mathrm{E}\left[\lambda_{f}\right]$ and assessed the corresponding panels' structural reliability (Table 1). The increases in strength are effective at decreasing $\mathrm{E}\left[\lambda_{f}\right]$. The strength factor of two reduces $\mathrm{E}\left[\lambda_{f}\right]$ by a factor of 3.9 and 2.5 for rooftop and ground-mounted panels, respectively. A more modest strength factor of 1.25 also effectively decreases panel failure risk, reducing $\mathrm{E}\left[\lambda_{f}\right]$ by $\sim 50 \%$ and $\sim 70 \%$ for rooftop and ground-mounted panels, respectively. Nevertheless, our results indicate that the reliability indexes for these stronger panels are still below the ASCE7-10 targets even for a risk category I, i.e., 1.9.

\begin{tabular}{|c|c|c|c|c|}
\hline \multicolumn{5}{|c|}{ Table 1. Annual probability of panel failure and reliability indexes (for 50 } \\
years) for different increases in strength \\
\hline \multirow{2}{*}{ Strength Factor } & \multicolumn{2}{|c|}{ Rooftop panel } & \multicolumn{2}{c|}{ Ground-mounted panels } \\
\cline { 2 - 5 } & $\mathrm{E}\left[\lambda_{f}\right](1 / \mathrm{yr})$ & $\begin{array}{c}\text { Reliability } \\
\text { index }\end{array}$ & $\mathrm{E}\left[\lambda_{f}\right](1 / y r)$ & $\begin{array}{c}\text { Reliability } \\
\text { index }\end{array}$ \\
\hline 1.0 & 0.0132 & 0.04 & 0.0020 & 1.30 \\
\hline 1.25 & 0.0089 & 0.36 & 0.0012 & 1.58 \\
\hline 1.50 & 0.0061 & 0.63 & 0.0010 & 1.66 \\
\hline 1.75 & 0.0043 & 0.87 & 0.0009 & 1.73 \\
\hline 2.0 & 0.0034 & 1.01 & 0.0008 & 1.77 \\
\hline
\end{tabular}

416

These results highlight large structural vulnerabilities in solar panels since they do not reach code-level reliability even if their strength is increased twice. These results suggest that existing lack of structural design and limited inspections in the panel installations were significant (Burgess et al., 2020; Burgess \& Goodman, 2018). High vulnerability to hurricane winds has been noted previously in buildings. For example, a previous study in Southern Florida determined that roof-to-wall connections with 3-8d toenails in wooden residential buildings have an annual failure rate between 0.005-0.024 (Li \& Ellingwood, 2006). These rates are comparable to the rooftop panels in our case study and below the performance of groundmounted panels (Table 1). Furthermore, roof panels with 6d nails @ 6/12 in. on these buildings showed even poorer performance, with higher annual failure rates of 0.077-0.137. 


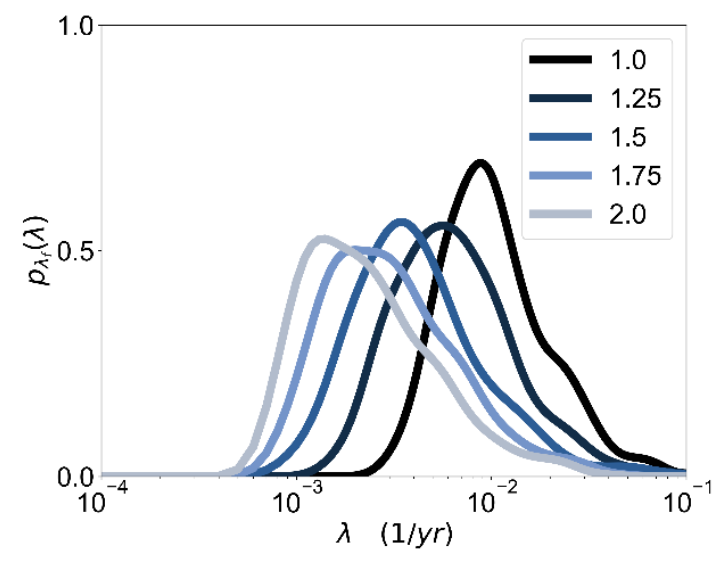

a) Rooftop panel

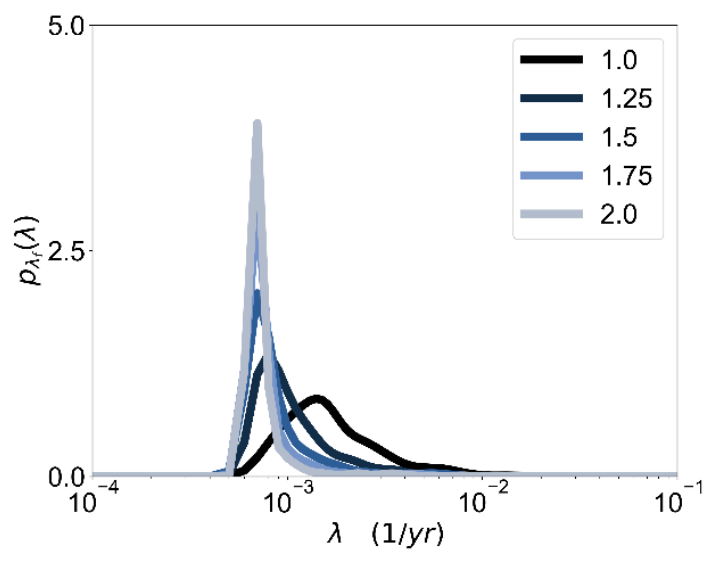

b) Ground-mounted panel

Figure 9. Probability density function of the annual failure rate of solar panels for different increases in panel strength. The labels indicate the strength factor increase.

\subsection{Will stronger panels increase generation resilience?}

As demonstrated previously, increasing panel strength will increase its reliability. However, other critical factors also play a significant role in solar generation resilience, i.e., the ability to generate sufficient electricity during storms. First, solar generation can decrease even if panels remain structurally sound and functional during a hurricane. Ceferino et al. (2021) demonstrated that hurricane clouds can reduce irradiance and generation significantly through light absorption and reflection. For example, a category-4 hurricane can decrease the generation by more than $70 \%$, even if the panels remain undamaged. Clouddriven generation losses can last for days, although they will bounce back to normal conditions in an undamaged panel as the hurricane leaves.

Failure of supporting infrastructure can also decrease generation resilience even if panels withstand extreme wind loads. Increasing the strength of rooftop panels on vulnerable roofs will not increase the global reliability of the residential energy system. Global reliability must consider that panels can fail in a cascading failure triggered by roof uplift, damaging the panel or its connections. The weakest link will control the reliability of this in-series system. As mentioned previously, roof-to-wall connections with 38d toe nails or roof panels with 6d nails @ 6/12" exhibited similar or poorer performance than vulnerable rooftop panels (Li \& Ellingwood, 2006). Strengthening panels on these roofs will substantially increase their local reliability (Table 1), but it will increase global reliability only negligibly. Conversely, roofs with H2.5 hurricane clips in roof-to-wall connections and 8d nails @ 6/12" in roof panels will make roofs an appropriate supporting system through higher reliability (Li \& Ellingwood, 2006). Thus, our results advocate for stronger panels but under a holistic assessment of global reliability.

Structurally sound rooftop panels have the intrinsic advantage of delivering power even if the primary grid is down. When inverters are within buildings, occupants can use their locally generated energy during an outage (Cook et al., 2020). Access to power can be vital for residential buildings, especially if heatwaves following storms increase the demand for cooling (Feng et al., 2021). Access to energy is also pivotal to sustaining emergency response operations for critical infrastructure such as hospitals or fire stations. Communities can further utilize locally generated energy through energy sharing and microgrids to increase households' access to power after a disaster, even for those who did not install panels (Ceferino et al., 2020; Patel et al., 2021). Nevertheless, solar panels will not replace the need for backup generation units for 
resilience, especially for critical facilities, and fully charged behind-the-meter batteries must complement them for power access during an emergency response.

458

459

460

461

462

463

464

465

466

467

468

469

470

471

472

473

474

475

476

477

478

479

480

481

482

483

484

485

486

487

488

489

490

491

492

493

494

495

496

497

498

499

Stronger panels will also increase power security at the utility level by avoiding massive structural failures at the generation sites, as in Figure 1b. As noted previously, solar panels are directly exposed to wind. Poor structural performance in utility companies' solar installations could result in significant generation losses and outages that can affect the disaster emergency response and recovery activities. Recently, Hurricane Ida caused damage to the power system that resulted in $\sim 1 \mathrm{M}$ outages in Louisiana, reducing electricity access by more than $60 \%$ in more than ten parishes (counties), critically affecting the functionality of the water system and delaying recovery (J. D. Goodman et al., 2021; Prevatt et al., 2021). While solar generation losses could be potentially offset by other generating sources during an emergency response, adopting vulnerable panels in our grid will be a missed opportunity to make our power systems resilient.

Solar is projected to be an important generation source in our future grids. Simultaneously, hurricanes are projected to be more intense in the future climate (Knutson et al., 2020). Governments invest massively to redesign the grid and transition to cleaner energy (The International Renewable Energy Agency, 2018). Thus, our results advocate for governments to leverage this unique opportunity to change the grid's risk trajectory course by strengthening the infrastructure that will provide our future communities with energy safety.

\section{CONCLUSIONS}

This paper presented the first data-driven fragility curves for solar panels under hurricane wind loads. The article estimated the fragility curves using data on the structural performance of 46 rooftop panels in residential buildings and 14 large ground-mounted solar panel arrays in utility generation sites. Solar panel failure data was collected after Hurricanes Maria and Irma in 2017 and Hurricane Dorian in 2019 in the Caribbean. Further, this paper assessed solar generation resilience and its improvements with stronger panels.

We used a Bayesian approach to supplement the panel dataset with an existing numerical assessment of panel failure. Using a Markov Chain Monte Carlo algorithm, we estimated the posterior distributions of fragility parameters for the rooftop and ground-mounted panels separately. Our results show significant reductions in epistemic uncertainty for $v$ (wind for a $50 \%$-failure probability) in rooftop and groundmounted panels with $90 \%$ and $87 \%$ decreases in the standard deviation. Using Monte Carlo, we then propagated the uncertainty in the parameters to the fragility functions, showing significantly narrower confidence intervals. This result highlighted the importance of characterizing fragility functions with ground-truth data.

We combined our fragility functions with a hurricane hazard assessment in Miami-Dade, Florida, using Monte Carlo simulations. Miami-Dade has similar hurricane hazards to Puerto Rico, where most damage data was collected. Our estimates of the annual rate of panel structural failure indicated that the panels are below the current structural reliability standards specified in ASCE7-16. These performance deficiencies were particularly striking for rooftop panels (estimated failure rate of $1.3 \times 10^{-2} / y r$ versus $2.3 \times 10^{-4} / y r$ in the code), whose documented installation issues and frequent lack of structural design made them particularly vulnerable to high winds.

Finally, we analyzed the implications of building stronger solar panels by up to a factor of two due to improvements in the panels' installations, structural design, or higher structural requirements. We show that increasing panel strength effectively reduces the annual failure rate. However, even the factor of two is still insufficient to meet annual failure rates in the ASCE7-10 (reliability index of 1.9 for the lowest risk category) for rooftop and ground-mounted panels (reliability indexes of 1.01 and 1.77). 
As we transition towards cleaner energy sources and solar generation becomes an essential component of our grid, ensuring its resilience is critical for our communities. Our paper argues that increasing panels' structural strength has critical implications for enhancing generation resilience during extreme storms. In the context of growing hurricane hazards due to climate change, panels must at least meet existing code structural performance standards. However, we also discuss that generation losses might arise even if panels can sustain high wind speeds. Thus, we point out different plans, such as using backup power, behind-the-meter storage, or sharing energy, to address such losses during hurricane emergencies in order to sustain a proper response to hurricanes.

\section{AKNOWLEDGMENTS}

We thank Sanya Detweiler from the Clinton Foundation, Chris Needham and Solar Frank Oudheusden from FCX Solar, and Christopher Burgess from the Rocky Mountain Institute for sharing their reports, photos, and relevant documentation on solar panels' structural performance after Hurricanes Maria and Irma in 2017 and Dorian in 2019. We also acknowledge the financial support by the Andlinger Center for Energy and the Environment at Princeton University through the Distinguished Postdoctoral Fellowship. Additionally, this research was also supported by the NSF Grant 1652448. The authors are grateful for their generous support.

\section{SUPPLEMENTARY INFORMATION}

Supplementary Tables 1 and 2 and Supplementary Figure 1 to 4 can be found at: https://tinyurl.com/mw224py5

\section{REFERENCES}

American Society of Civil Engineers. (2017). Minimum design loads and associated criteria for buildings and other structures. In Minimum Design Loads and Associated Criteria for Buildings and Other Structures. https://doi.org/10.1061/9780784414248

American Society of Civil Engineers (ASCE). (2017). Minimum Design Loads and Buildings and Other Structures (ASCE/SEI 7-16).

Bennett, J. A., Trevisan, C. N., Decarolis, J. F., Ortiz-garcía, C., Pérez-lugo, M., Etienne, B. T., \& Clarens, A. F. (2021). Extending energy system modelling to include extreme weather risks and application to hurricane events in Puerto Rico. Nature Energy, 6(March). https://doi.org/10.1038/s41560-020-00758-6

Burgess, C., Detweiler, S., Needham, C., \& Oudheusden, F. (2020). Solar Under Storm Part II: Select Best Practices for Resilient Roof-Mount PV Systems with Hurricane Exposure. www.clintonfoundation.org/Solar-

Burgess, C., \& Goodman, J. (2018). Solar Under Storm. Select Best Practices for Resilient GroundMount PV Systems with Hurricane Exposure. https://www.rmi.org/wpcontent/uploads/2018/06/Islands_SolarUnderStorm_Report_digitalJune122018.pdf

Cain, J. H., Banks, D., \& Petersen, C. P. (2015). Wind Loads on Utility Scale Solar PV Power Plants. 2015 SEAOC Convention Proceedings, 1-8. http://www.cppwind.com/wpcontent/uploads/2014/01/Wind-Loads-on-Utility-Scale-Solar-PV-Power-Plants_DBanks_2015.pdf

Ceferino, L., Lin, N., \& Xi, D. (2021). Stochastic Modeling of Solar Irradiance during Hurricanes. In review. https://engrxiv.org/pu5da/ 
Ceferino, L., Liu, C., Alisjahbana, I., Patel, S., Sun, T., Kiremidjian, A., \& Rajagopal, R. (2020). Earthquake resilience of distributed energy resources. 17th World Conference on Earthquake Engineering.

Chavas, D. R., Lin, N., \& Emanuel, K. (2015). A model for the complete radial structure of the tropical cyclone wind field. Part I: Comparison with observed structure. Journal of the Atmospheric Sciences, 72(9), 3647-3662. https://doi.org/10.1175/JAS-D-15-0014.1

Chib, S., \& Greenberg, E. (1995). Understanding the Metropolis-Hastings Algorithm. The American Statistician, 49(4), 327-335. http://www.jstor.org/stable/2684568

Cook, J., Hotchkiss, E., Li, X., \& Cruce, J. (2020). Planning for the Storm : Considering Renewable Energy for Critical Infrastructure Resilience. Journal of Emergency Management, 18(4). https://www.nrel.gov/docs/fy20osti/75804.pdf

Ellingwood, B. R., Rosowsky, D. v., Li, Y., \& Kim, J. H. (2004). Fragility Assessment of Light-Frame Wood Construction Subjected to Wind and Earthquake Hazards. Journal of Structural Engineering, 130(12), 1921-1930. https://doi.org/10.1061/(ASCE)0733-9445(2004)130:12(1921)

Emanuel, K., Sundararajan, R., \& Williams, J. (2008). Hurricanes and Global Warming: Results from Downscaling IPCC AR4 Simulations. Bulletin of the American Meteorological Society, 89(3), 347368. https://doi.org/10.1175/BAMS-89-3-347

Federal Emergency Management Agency (FEMA). (2020). Building Codes Save: A Nationwide Study. Losses Avoided as a Result of Adoption Hazard-Resistant Building Codes (Issue November). https://www.fema.gov/sites/default/files/2020-11/fema_building-codes-save_study.pdf

Feng, K., Min, O., \& Lin, N. (2021). The hurricane-blackout-heatwave compound hazard risk and resilience in a changing climate.

Gelman, A., Carlin, J. B., Stern, H. S., Dunson, D. B., Vehtari, A., \& Rubin, D. B. (2013). Bayesian Data Analysis. In Bayesian Data Analysis (Third edit). https://doi.org/10.1201/b16018

Goodman, J. D., Heyward, G., \& Kasakove, S. (2021, August 31). Louisiana's governor tells evacuees not to return until infrastructure is restored. New York Times. https://www.nytimes.com/live/2021/08/31/us/hurricane-ida-updates

Goodman, J. N. (2015). Performance Measures for Residential PV Structural Response to Wind Effects (Issue December).

Institute for Energy Research. (2018). Much of Puerto Rico's Wind and Solar Power Is Not Yet Operational. https://www.instituteforenergyresearch.org/the-grid/much-of-puerto-ricos-wind-andsolar-power-is-not-yet-operational/\#: :text=Two renewable facilities on Puerto,Rico's fastest growing renewable resource.

Knutson, T., Camargo, S. J., Chan, J. C. L., Emanuel, K., Ho, C. H., Kossin, J., Mohapatra, M., Satoh, M., Sugi, M., Walsh, K., \& Wu, L. (2020). Tropical cyclones and climate change assessment part II: Projected response to anthropogenic warming. Bulletin of the American Meteorological Society, 101(3), E303-E322. https://doi.org/10.1175/BAMS-D-18-0194.1

Kwasinski, A. (2018). Effects of Hurricane Maria on Renewable Energy Systems in Puerto Rico. 7th International IEEE Conference on Renewable Energy Research and Applications, ICRERA 2018, 5, 383-390. https://doi.org/10.1109/ICRERA.2018.8566922

Landsea, C. W., \& Franklin, J. L. (2013). Atlantic hurricane database uncertainty and presentation of a new database format. Monthly Weather Review, 141(10), 3576-3592. https://doi.org/10.1175/MWRD-12-00254.1 
Lin, N., Emanuel, K., Oppenheimer, M., \& Vanmarcke, E. (2012). Physically based assessment of hurricane surge threat under climate change. Nature Climate Change, 2(6), 462-467. https://doi.org/10.1038/nclimate 1389

Liu, J. S. (2004). Monte Carlo Strategies in Scientific Computing. Springer New York. https://doi.org/10.1007/978-0-387-76371-2

Li, Y., \& Ellingwood, B. R. (2006). Hurricane damage to residential construction in the US: Importance of uncertainty modeling in risk assessment. Engineering Structures, 28(7), 1009-1018. https://doi.org/10.1016/j.engstruct.2005.11.005

Marsooli, R., Lin, N., Emanuel, K., \& Feng, K. (2019). Climate change exacerbates hurricane flood hazards along US Atlantic and Gulf Coasts in spatially varying patterns. Nature Communications, 10(1), 1-9. https://doi.org/10.1038/s41467-019-11755-z

McAllister, T. P., Wang, N., \& Ellingwood, B. R. (2018). Risk-Informed Mean Recurrence Intervals for Updated Wind Maps in ASCE 7-16. Journal of Structural Engineering, 144(5), 06018001. https://doi.org/10.1061/(asce)st.1943-541x.0002011

Mitsova, D., Escaleras, M., Sapat, A., Esnard, A. M., \& Lamadrid, A. J. (2019). The effects of infrastructure service disruptions and socio-economic vulnerability on Hurricane recovery. Sustainability, 11(2), 1-16. https://doi.org/10.3390/su11020516

National Oceanographic and Atmospheric Administration. (2021). Hurricane Maria Imagery. https://storms.ngs.noaa.gov/storms/maria/index.html\#16/

NOAA National Centers for Environmental Information. (2001). Global Surface Hourly (Wind). NOAA National Centers for Environmental Information.

Noh, H. Y., Kiremidjian, A., Ceferino, L., \& So, E. (2017). Bayesian Updating of Earthquake Vulnerability Functions with Application to Mortality Rates. Earthquake Spectra, 33(3), 11731189. https://doi.org/10.1193/081216EQS133M

Patel, S., Ceferino, L., Liu, C., Kiremidjian, A., \& Rajagopal, R. (2021). The disaster resilience value of shared rooftop solar systems in residential communities. Earthquake Spectra, June, 1-24. https://doi.org/10.1177/87552930211020020

Perea, A., Smith, C., Davis, M., Mond, A., Gallagher, B., Rumery, S., Holm, A., Goldstein, R., \& Baca, J. (2019). U. S. Solar Market Insight Executive Summary.

Prevatt, D., Kameshwar, S., Roueche, D., Rittelmeyer, B., Duarte, T., Heo, T., Ibrahim, H., Klepac, S., Lafontaine, O., Lin, T., Manuel, L., Pilkington, S., Pinyochotiwong, Y., Santiago-Hernandez, J., Strader, S., Gurley, K., Kijewski-Correa, T., Mosalam, K., \& Robertson, I. (2021). StEER: Hurricane Ida Joint Preliminary Virtual Reconnaissance Report - Early Access Reconnaissance Report (PVRR-EARR) (Issue August). https://doi.org/10.17603/ds2-w6km-fe51

Robert, C. P. (2014). The Metropolis-Hastings algorithm. Wiley StatsRef: Statistics Reference Online, 115. https://doi.org/10.1002/9781118445112.stat07834

Roueche, D. B., Lombardo, F. T., \& Prevatt, D. O. (2017). Empirical Approach to Evaluating the Tornado Fragility of Residential Structures. Journal of Structural Engineering, 143(9), 04017123. https://doi.org/10.1061/(asce)st.1943-541x.0001854

Roueche, D. B., Lombardo, F. T., Smith, D. J., \& Krupar, R. J. (2018). Fragility assessment of windinduced residential building damage caused by hurricane harvey, 2017. Forensic Engineering 2018: Forging Forensic Frontiers - Proceedings of the 8th Congress on Forensic Engineering, 1984, 1039-1048. https://doi.org/10.1061/9780784482018.100 
Shah, V. ;, \& Booream-Phelps, J. C. (2015). Crossing the Chasm: Solar Grid Parity in a Low Oil Price Era. https://www.db.com/cr/en/concrete-deutsche-bank-report-solar-grid-parity-in-a-low-oil-priceera.htm

Shinozuka, M., Feng, M. Q., Lee, J., \& Naganuma, T. (2000). Statistical Analysis of Fragility Curves. Journal of Engineering Mechanics, 126(12), 1224-1231. https://doi.org/10.1061/(ASCE)07339399(2000)126:12(1224)

Sivaram, V., \& Kann, S. (2016). Solar power needs a more ambitious cost target. Nature Energy, 1(4), 16036. https://doi.org/10.1038/nenergy.2016.36

Solaun, K., \& Cerdá, E. (2019). Climate change impacts on renewable energy generation. A review of quantitative projections. Renewable and Sustainable Energy Reviews, 116(109415). https://doi.org/10.1016/j.rser.2019.109415

Straub, D., \& der Kiureghian, A. (2008). Improved seismic fragility modeling from empirical data. Structural Safety, 30(4), 320-336. https://doi.org/10.1016/j.strusafe.2007.05.004

The International Renewable Energy Agency. (2018). Global Energy Transformation: A Rodmap to 2050. In Global Energy Transformation.

U.S. Energy Information Administration. (2021). Electricity explained: Electricity generation, capacity, and sales in the United States. https://www.eia.gov/energyexplained/electricity/electricity-in-the-usgeneration-capacity-and-sales.php

Vickery, P., \& Skerlj, P. (2005). Hurricane Gust Factors Revisited. Journal of Structural Engineering, 131(5), 825-832. https://doi.org/10.1061/(ASCE)0733-9445(2005)131

Watson, Eileen. B. (2018). Modeling Electrical Grid Resilience under Hurricane Wind Conditions with Increased Solar Photovoltaic and Wind Turbine Power Generation. https://doi.org/10.1542/peds.2006-2099

Winkler, J., Dueñas-Osorio, L., Stein, R., \& Subramanian, D. (2010). Performance assessment of topologically diverse power systems subjected to hurricane events. Reliability Engineering and System Safety, 95(4), 323-336. https://doi.org/10.1016/j.ress.2009.11.002

Zhai, C., Chen, T. Y. jeh, White, A. G., \& Guikema, S. D. (2021). Power outage prediction for natural hazards using synthetic power distribution systems. Reliability Engineering and System Safety, 208(November 2020). https://doi.org/10.1016/j.ress.2020.107348 